\title{
Percepções de estudantes sobre bullying e família: um enfoque qualitativo na saúde do escolar
}

\section{Perceptions of students on bullying and the family: a qualitative focus on school health}

\author{
Wanderlei Abadio de Oliveira (D), Jorge Luiz da Silva², lara Falleiros Braga³, \\ Claudio Romualdo ${ }^{1}$, Waldemar Brandão Neto ${ }^{4}$, Simona Carla Silvia Caravita ${ }^{5}$, \\ Marta Angélica Iossi Silva ${ }^{1}$
}

\begin{abstract}
Resumo
Introdução: O bullying escolar representa um fenômeno expressivo no Brasil e no mundo, impactando na saúde e no desenvolvimento de crianças e adolescentes. Objetivo: Analisar as relações entre as percepções de estudantes sobre bullying escolar e interações familiares. Método: Trata-se de um estudo qualitativo, do qual participaram 55 estudantes. Entrevistas semiestruturadas foram utilizadas na coleta de dados e analisadas segundo a análise de conteúdo, em sua modalidade temática, no software Atlas.Ti. O referencial teórico-metodológico adotado foi a Teoria Bioecológica do Desenvolvimento. Resultados: Revelou-se que a) as características individuais, resultantes do processo de desenvolvimento que envolve a família, são os fatores que melhor explicam o bullying; b) as experiências negativas no contexto familiar podem favorecer o envolvimento dos estudantes em situações de bullying; e c) aspectos positivos das famílias podem ser considerados pontos fortes a serem explorados por programas de intervenção. Conclusão: Foram identificadas relações entre as percepções acerca do bullying escolar e as interações familiares. A investigação aumenta a compreensão sobre a complexidade do bullying e poderá subsidiar iniciativas de formação de profissionais que atuam na área da saúde e têm as famílias como matriz de ação na atenção primária.
\end{abstract}

Palavras-chave: saúde escolar; saúde do adolescente; relações familiares; violência; bullying.

\begin{abstract}
Background: School bullying represents an expressive phenomenon in Brazil and in the world, impacting in the health and development of children and adolescents. Objective: To analyze the relationships between student perceptions of school bullying and family interactions. Method: This is a qualitative study, in which 55 students participated. Semi-structured interviews were used in the data collection and analyzed according to the content analysis, in its thematic modality, in the software Atlas.Ti. The theoretical-methodological reference adopted was the Bioecological Theory of Development. Results: It was revealed that a) individual characteristics resulting from the development process involving the family are the factors that best explain bullying; b) negative experiences in the family context can favor the involvement of students in situations of bullying; and c) positive aspects of families can be considered as strengths to be explored by intervention programs. Conclusion: Relationships between perceptions
\end{abstract}

'Escola de Enfermagem de Ribeirão Preto, Universidade de São Paulo (USP) - Ribeirão Preto (SP), Brasil.

¿Universidade de Franca (UNIFRAN), Franca (SP), Brasil.

${ }^{3}$ Universidade Federal da Paraíba (UFPB) - João Pessoa (PB), Brasil.

${ }^{4}$ Universidade de Pernambuco (UPE) - Recife (PE), Brasil.

${ }^{5}$ Facoltà di Psicologia, Università Cattolica del Sacro Cuore - Milano (LO), Italia.

Trabalho realizado em 11 escolas públicas de Uberaba (MG), Brasil.

Endereço para correspondência: Wanderlei Abadio de Oliveira - Escola de Enfermagem de Ribeirão Preto, Universidade de São Paulo (USP), Avenida Bandeirantes, 3900, Sala 75 - Monte Alegre - CEP: 14040-902 - Ribeirão Preto (SP), Brasil - Email: wanderleio@hotmail.com; wanderleio@usp.br Fonte de financiamento: FAPESP (Processo 2014/13062-7); CAPES (Processo 7029/14-4).

Conflito de interesses: nada a declarar. 
about school bullying and family interactions were identified. The research increases understanding about the complexity of bullying and may subsidize initiatives for the training of professionals who work in the health area and have the families as a matrix of action in primary care.

Keywords: chool health; adolescent health; family relationships; violence; bullying

\section{INTRODUÇÃO}

O bullying é um dos principais problemas para a saúde e o desenvolvimento de crianças e adolescentes em idade escolar. Ele se refere a um tipo de violência caracterizado por sua natureza repetitiva, pela intencionalidade e pelo desequilíbrio de poder existente entre vítimas e agressores ${ }^{1}$. As vítimas se apresentam como pessoas que sofrem agressões e têm dificuldades de se defender, ao passo que os agressores adotam comportamentos agressivos ou violentos e possuem maior poder simbólico em relação às vítimas ${ }^{1}$. As principais maneiras de manifestação do fenômeno no contexto escolar são as agressões físicas, verbais, indiretas (em que não há confronto direto entre as partes envolvidas) e o cyberbullying ${ }^{2}$.

No que se refere às taxas de prevalência do fenômeno, observam-se variações nos diferentes contextos. Uma meta-análise que incluiu 80 estudos internacionais revelou médias de prevalência de 35\% de bullying tradicional (agressões diretas e indiretas) ${ }^{3}$. Na Europa e na América do Norte, um estudo transnacional, desenvolvido em 33 países, demonstrou que a vitimização possui uma ocorrência comum na maioria dos países investigados, com relatos de vitimização crônica de um a cada oito estudantes ${ }^{4}$. No Brasil, a Pesquisa Nacional de Saúde do Escolar (PeNSE) identificou uma prevalência de 7,2\% de vítimas e $21,8 \%$ de agressores em uma amostra nacional composta por 104.109 estudantes $^{5}$.

As principais causas relacionadas à sua ocorrência se referem às características individuais dos estudantes que os diferenciam em relação ao grupo de pares, da vulnerabilidade de um estudante em relação aos demais ou do status social que diferencia e segrega os estudantes ${ }^{5,6}$. Entre as consequências para os estudantes envolvidos em situações como essas estão problemas no processo ensino-aprendizagem (fracasso ou abandono escolar, por exemplo), adoecimentos (quadros de baixa autoestima, ansiedade e depressão) e adoção de comportamentos infracionais, uso de álcool ou outras drogas ou de criminalidade na juventude e vida adulta ${ }^{2,7}$.

Percebe-se, contudo, que apesar do aumento no número de pesquisa sobre os comportamentos de bullying ao longo das últimas décadas, grande parte da pesquisa se concentrou no diagnóstico da questão e na focalização das características individuais dos estudantes ${ }^{8}$. Sobretudo no Brasil, onde ainda existem desafios na compreensão do fenômeno a partir da abordagem de outras facetas a ele relacionadas. Internacionalmente, por exemplo, alguns estudos ${ }^{9-11}$ têm sugerido que aspectos das relações e interações familiares, como o tipo de comunicação, as manifestações de afeto e aspectos socioeconômicos das famílias, são determinantes para os envolvimentos dos estudantes em situações de bullying, assim como podem oferecer fatores de proteção para as vítimas, ou mesmo para impedir que um estudante se torne um agressor.

Esse cenário de índices de prevalência, as consequências e as múltiplas facetas do bullyingo converteram em um problema a ser inserido na agenda de pesquisa e atuação na área da saúde pública $^{12}$. A complexidade e o impacto global desse tipo de violência indicam que sua redução somente será possível a partir de programas de intervenção planejados intersetorialmente e capazes de congregar esforços com foco na eliminação de situações contextuais que possam vulnerabilizar crianças e adolescentes e fortalecer os fatores de proteção ${ }^{8,13}$. Dessa forma, analisando os efeitos que as interações familiares podem refletir nos comportamentos de crianças e adolescentes, profissionais atuantes na Estratégia Saúde da Família, por meio do contato direto e do vínculo com as famílias, são personagens-chave que, muitas vezes, não possuem os conhecimentos necessários para propor ações de cuidado e atenção com foco no bullying ${ }^{14}$. Esse estudo poderá subsidiar, assim, momentos de reflexão nas equipes de saúde sobre a problemática e auxiliar na atenção aos adolescentes vitimizados e, também, aqueles que praticam o bullying.

No campo dessa discussão, este artigo recorre à Teoria Bioecológica do Desenvolvimento de Bronfenbrenner para compreender a dinâmica entre as duas variáveis em análise (bullying e interações familiares). Sumariamente, essa teoria concebe o desenvolvimento como contínuo e resultado da interação entre as características individuais de cada pessoa e o contexto social ${ }^{15}$. O desenvolvimento é tido como um processo que ocorre em cinco níveis sucessivos, quais sejam: 1) individual (características biológicas e subjetivas); 2) microssistema (relações próximas da pessoa em desenvolvimento, como a família e a escola); 3 ) mesossistema (relação entre dois microssistemas em que a pessoa em desenvolvimento está inserida, como a família e a escola se relacionando); 4) exossistema (relação indireta com a pessoa em desenvolvimento, como o trabalho dos pais); 5) macrossistema (questões sociais, políticas, sistema de crenças e cultura do contexto da pessoa em desenvolvimento) $)^{15,16}$.

Nesse sentido, a partir de dados de uma revisão de literatura nacional e internacional ${ }^{8,13}$, identificou-se uma compreensão limitada no Brasil sobre 1) as histórias familiares de estudantes envolvidos em situações de bullying escolar; e 2) as implicações das experiências na família presentes nas justificativas ou explicações para o fenômeno. Para ajudar a preencher esta lacuna, 
uma pesquisa qualitativa foi desenvolvida com o objetivo de conhecer as percepções de estudantes sobre bullying escolar e interações familiares, e analisar as relações possíveis entre essas duas variáveis nas narrativas dos participantes.

\section{MÉTODO}

\section{Tipo e cenário do estudo}

Estudo com delineamento qualitativo, do tipo descritivo e exploratório, desenvolvido em uma cidade do interior do estado de Minas Gerais. A seleção da cidade ocorreu por conveniência.

\section{Participantes}

Este estudo apresenta resultados qualitativos de um grande estudo transversal, com delineamento misto, sobre bullying e interações familiares. Assim, 2.354 estudantes (50,6\% meninas; idade média 14,50 anos, $D P=2,01$ anos), de 11 escolas públicas, participaram da etapa quantitativa, que consistia na aplicação de duas escalas de autopreenchimento sobre bullying e interações familiares.
Na etapa qualitativa, foco neste artigo, cinco estudantes de cada uma das 11 escolas foram sorteados randomicamente para serem entrevistados, totalizando 55 adolescentes (46,5\% meninas; idade média 15 anos, $D P=2$ anos). A Tabela 1 apresenta alguns aspectos que permitem caracterizar os participantes do estudo.

A seleção dos participantes para essa etapa foi orientada pela estratégia de amostragem por variação máxima ${ }^{17}$. Os critérios de inclusão dos participantes no estudo foram: 1) estar matriculado no ensino fundamental ou médio de uma das escolas selecionadas; 2) participar da primeira etapa quantitativa do estudo maior em desenvolvimento; e 3) estar presente em aula no dia da entrevista. Neste artigo, optou-se por abordar apenas os dados relacionados aos estudantes que referiram ser vítimas $(n=16)$ ou agressores $(n=8)$.

\section{Procedimentos}

A coleta de dados foi realizada entre agosto e outubro de 2014. Entre os 2.354 estudantes que responderam duas escalas (sobre bullying e interações familiares) que compõem a etapa

Tabela 1. Caracterização (geral e por sexo) do grupo de participantes $(\mathrm{N}=55)$

\begin{tabular}{|c|c|c|c|c|c|c|c|c|}
\hline & \multicolumn{4}{|c|}{ Total } & \multicolumn{4}{|c|}{ Sexo } \\
\hline & \multirow{2}{*}{$\mathbf{N}$} & \multirow{2}{*}{$\%$} & \multirow{2}{*}{ Fac } & \multirow{2}{*}{ Fra } & \multicolumn{2}{|c|}{ Masculino } & \multicolumn{2}{|c|}{ Feminino } \\
\hline & & & & & $\mathbf{N}$ & $\%$ & $\mathbf{N}$ & $\%$ \\
\hline \multicolumn{9}{|l|}{ Idade } \\
\hline 11 & 2 & 4,00 & 2 & 4,00 & 1 & 1,90 & 1 & 2,00 \\
\hline 12 & 6 & 11,00 & 8 & 15,00 & 2 & 3,70 & 4 & 7,20 \\
\hline 13 & 10 & 18,00 & 18 & 33,00 & 5 & 9,40 & 5 & 9,00 \\
\hline 14 & 6 & 11,00 & 24 & 44,00 & 2 & 3,70 & 4 & 7,20 \\
\hline 15 & 6 & 11,00 & 30 & 55,00 & 4 & 7,00 & 2 & 3,60 \\
\hline 16 & 11 & 20,00 & 41 & 75,00 & 8 & 14,80 & 3 & 5,40 \\
\hline 17 & 8 & 14,00 & 49 & 89,00 & 4 & 7,00 & 4 & 7,20 \\
\hline 18 & 6 & 11,00 & 55 & 100 & 3 & 5,50 & 3 & 5,40 \\
\hline \multicolumn{9}{|l|}{ Ano escolar } \\
\hline $6^{\circ}$ ano Ensino Fundamental & 3 & 6,00 & 3 & 6,00 & 1 & 1,90 & 2 & 3,60 \\
\hline $7^{\circ}$ ano Ensino Fundamental & 8 & 15,00 & 11 & 21,00 & 4 & 7,20 & 4 & 7,20 \\
\hline $8^{\circ}$ ano Ensino Fundamental & 12 & 22,00 & 23 & 43,00 & 6 & 11,10 & 6 & 10,60 \\
\hline $9^{\circ}$ ano Ensino Fundamental & 3 & 6,00 & 26 & 49,00 & 2 & 3,70 & 1 & 2,00 \\
\hline $1^{\circ}$ ano Ensino Médio & 9 & 15,00 & 35 & 64,00 & 4 & 7,00 & 5 & 9,00 \\
\hline $2^{\circ}$ ano Ensino Médio & 17 & 30,00 & 52 & 94,00 & 10 & 18,40 & 7 & 12,60 \\
\hline $3^{\circ}$ ano Ensino Médio & 3 & 6,00 & 55 & 100 & 2 & 3,70 & 1 & 2,00 \\
\hline \multicolumn{9}{|l|}{ Arranjo familiar/com quem viviam } \\
\hline Pai e mãe & 13 & 24,00 & 13 & 24,00 & 8 & 14,80 & 5 & 9,00 \\
\hline Pai, mãe e irmão(s) & 17 & 30,00 & 30 & 54,00 & 8 & 14,80 & 9 & 16,00 \\
\hline Pai, mãe, irmão(s) e/ou outras pessoas & 3 & 6,00 & 33 & 60,00 & 2 & 3,70 & 1 & 2,00 \\
\hline Somente com a mãe & 4 & 7,00 & 37 & 67,00 & 3 & 5,50 & 1 & 2,00 \\
\hline Pai e outras pessoas & 1 & 2,00 & 38 & 69,00 & 1 & 1,90 & 0 & 0,00 \\
\hline Mãe e outras pessoas & 14 & 25,00 & 52 & 94,00 & 7 & 12,30 & 7 & 12,60 \\
\hline Outras pessoas & 3 & 6,00 & 55 & 100 & 0 & 0,00 & 3 & 5,40 \\
\hline
\end{tabular}

Fac $=$ Frequência absoluta acumulada; Fra $=$ Frequência relativa absoluta 
quantitativa do estudo maior, foram sorteados os estudantes para as entrevistas semiestruturadas. As entrevistas foram realizadas nas escolas, pelo primeiro autor do estudo, em salas reservadas, sem a presença de professores ou outros estudantes. O tempo médio de cada entrevista foi de 12 minutos, com variação entre 6 e 26 minutos. As entrevistas foram gravadas e transcritas na íntegra.

\section{Instrumento}

Um roteiro baseado em estudos ${ }^{18,19}$ relacionados à pesquisa qualitativa foi construído para orientar as entrevistas semiestruturadas. São exemplos de perguntas do roteiro: Como é sua relação com seus pais, com sua família? Você já foi ameaçado, humilhado, excluído ou agredido na escola? Ou ameaçou, maltratou, humilhou, excluiu ou agrediu outro colega? Pense nas coisas que acontecem na sua casa: você acha que elas interferem no seu jeito de ser ou nas coisas que acontecem com você em outros lugares (de que forma)? Também foram utilizadas perguntas de acompanhamento para esclarecer ou aprofundar as respostas, bem como para permitir a exclusão de situações pontuais ou de outro tipo de violência que não se caracterizavam como bullying (Como assim? O que você quer dizer? Você poderia me dar exemplos? etc.).

\section{Análise de dados}

As transcrições das entrevistas foram importadas para o software Atlas.TI versão 7, e o processo de análise envolveu dois níveis: 1) desenvolvimento de códigos a partir da leitura exaustiva das entrevistas; e 2) construção de categorias temáticas segundo os princípios da análise de conteúdo, em sua modalidade temática ${ }^{20,21}$. Destaca-se que um pesquisador responsável aplicou o esquema para o desenvolvimento dos códigos no software, e um segundo investigador voluntário revisou a codificação e as decisões tomadas. Os dois pesquisadores se reuniram para chegar a consensos em casos de discordância. Do conjunto de dados emergiram cinco categorias temáticas. $\mathrm{O}$ processo de análise e interpretação também foi orientado pelos aportes da Teoria Bioecológica do Desenvolvimento ${ }^{15}$.

\section{Questões éticas}

O estudo foi aprovado pelo Comitê de Ética em Pesquisa da Escola de Enfermagem de Ribeirão Preto, Universidade de São Paulo (Parecer 484.912/2013). Os adolescentes participantes e seus responsáveis assinaram termos de assentimento e consentimento. Os nomes dos participantes foram substituídos por códigos relacionados ao sexo, ao número da entrevista, à idade e ao tipo de envolvimento em situações de bullying (por exemplo, participante 13: Menina 13, 13 anos, vítima; participante 18: Menino 18, 13 anos, agressor; e assim sucessivamente).

\section{RESULTADOS}

Foram realizadas 55 entrevistas semiestruturadas e identificadas cinco categorias temáticas. No Quadro 1 são apresentados fragmentos das entrevistas que exemplificam os aspectos abordados nas categorias temáticas que são apresentadas a seguir, separadamente.

\section{Categoria temática 1: influências familiares}

Segundo os adolescentes, a base familiar parece ser o que mais influencia e se relaciona com a maneira como os estudantes são na escola. Pormenorizadamente, as experiências de conflito ou de situações-limite (brigas, punições corporais etc.) afetam a experiência escolar dos adolescentes. Além disso, para os participantes é na família que são construídos princípios e valores que serão vivenciados na escola. Houve uma percepção majoritária de que a família é um espaço educativo. Os participantes vitimizados mencionaram que os pais os estimulam, muitas vezes, a ignorar as agressões.

\section{Categoria temática 2: questões éticas e morais}

Identificou-se o uso de mecanismos de desengajamento moral para justificar as agressões praticadas pelos estudantes. Os mecanismos utilizados por esses participantes (agressores) foram a difusão de responsabilidade (diluindo o senso de responsabilidade com outras pessoas), o uso de eufemismos (justificam a ação como algo não grave) e a culpabilização da vítima pelas agressões. Sobre esse processo de culpabilização, observou-se que as vítimas do sexo feminino apresentam um comportamento análogo de internalização da culpa pelas agressões. Os estudantes identificados como agressores ainda manifestaram sentimentos de hedonismo e intencionavam causar sofrimento às vítimas. Além disso, eles também personificavam a experiência de bullying, considerando que ela é errada quando se refere a uma agressão cuja justificativa seja uma característica da vítima que se assemelha a um membro de suas famílias. As vítimas exprimiram em maior quantidade reflexão ética e moral quando se referiram a outras vítimas.

\section{Categoria temática 3: ambientes vulneráveis}

O principal ponto abordado nessa categoria se refere a ambientes que não são percebidos como saudáveis ou produtores de saúde, bem como são marcados pelo desamparo em face das experiências negativas. Por exemplo: a longa jornada de trabalho dos pais, os conflitos intrafamiliares, a comunicação negativa ou inexistente, episódios de punição corporal e a saúde física e mental das mães. A baixa participação dos pais na vida dos filhos (nível de envolvimento familiar), medida pela referência a poucas demonstrações de afeto, carência de apoio e estímulo à autonomia, foi outro aspecto identificado. Além disso, estudantes vítimas e agressores expressaram sentimentos de desamparo em suas famílias. 
Quadro 1. Categorias temáticas e fragmentos extraídos das entrevistas com agressores e vítimas de bullying, 2017

\begin{tabular}{|c|c|}
\hline $\begin{array}{c}\text { Categorias } \\
\text { temáticas }\end{array}$ & Fragmentos extraídos das entrevistas \\
\hline $\begin{array}{l}\text { Influências } \\
\text { familiares }\end{array}$ & $\begin{array}{l}\text { Se meu pai e minha mãe brigasse ou separasse isso influenciaria no meu comportamento na escola (Menino } 18,13 \text { anos, } \\
\text { agressor). } \\
\text { Vai bater, aí depois, por exemplo, o filho fica ainda mais revoltado e depois vai querer fazer mais coisas erradas. Agora se } \\
\text { os pais sentarem e conversarem, os filhos vão pensar, conversar, refletir (Menina } 28,13 \text { anos, vítima). } \\
\text { Lá em casa eu recebo muita educação do meu pai e da minha mãe. Respeitar os outros, não xingar, não brigar, não } \\
\text { revidar, essas coisas (Menino 16, } 12 \text { anos, vítima). } \\
\text { Minha mãe fala que a minha irmã faz tudo certo e eu às vezes faço tudo errado (Menina 13, } 13 \text { anos, vítima). } \\
\text { Minha mãe me orientou que não é para eu caçar briga. Que é para eu ficar mais quieto no meu canto, não conversar } \\
\text { com eles. Eu fico mais quieto no meu canto (Menino 35, } 13 \text { anos, vítima). }\end{array}$ \\
\hline $\begin{array}{l}\text { Questões éticas e } \\
\text { morais }\end{array}$ & $\begin{array}{l}\text { Eu fui pela cabeça dos outros: "Maria vai com as outras" (Menina 38, } 17 \text { anos, agressora). } \\
\text { Ela gostava de aparecer nas nossas costas. A gente ficava batendo nela (Menina 4, } 14 \text { anos, agressora). } \\
\text { Hoje se alguém me crítica, eu falo: tem razão. Eu acredito no que ela está falando (Menina 45, } 19 \text { anos, vítima). } \\
\text { Na época, eu pensava assim: eu vou fazer isso para não fazerem comigo. Agora, hoje, não, eu penso que eu fazia isso } \\
\text { para fazer graça, para aparecer (Menino 9, } 17 \text { anos, agressor). } \\
\text { Teve uma hora que eu não gostei, mas deu um alívio ver ela chorando (Menina 4, } 14 \text { anos, agressora). } \\
\text { Tinha um moleque que chegou a agredir ela. Eu entrei na frente, [...] falei que ele não ia bater na menina [...]. Eu não } \\
\text { acho certo bater, muito menos em uma mulher. Não importa qual (Menino 3, } 13 \text { anos, agressor). }\end{array}$ \\
\hline $\begin{array}{l}\text { Ambientes } \\
\text { vulneráveis }\end{array}$ & $\begin{array}{l}\text { O meu pai não fica muito em casa, eu quase não vejo ele (Menino } 8,16 \text { anos, agressor). } \\
\text { Eu me sinto perdida, por causa que não tem aquele amor de mãe, não tem aquele amor de pai (Menina } 38,17 \text { anos, agressora). } \\
\text { Vivia em discussão, briga feia, todo dia tinha briga, todo dia [...]. Meu pai era caminhoneiro, então vinha em casa } \\
\text { só no final de semana e ele vinha só beber, ficar com os amigos, deixava minha mãe chateada, deixava nós jogados } \\
\text { (Menina } 38,17 \text { anos, agressora). } \\
\text { Eu não sou muito de conversar com os meus pais, porque eu converso com minha mãe, por exemplo, um minuto depois } \\
\text { minha mãe fica jogando na minha cara (Menina } 28,13 \text { anos, vítima). } \\
\text { A minha mãe me bate mais do que meu pai (Menina } 28,13 \text { anos, vítima). } \\
\text { Tem dias que dá vontade de sumir. Porque a minha mãe tem que tomar um medicamento durante cinco anos, todos os } \\
\text { dias e ela fica muito estressada, muito nervosa (Menina } 7,16 \text { anos, vítima). } \\
\text { A minha mãe tem um problema de estresse. Às vezes ela grita muito comigo, fica me comparando com a minha irmã, } \\
\text { mas aí depois eu percebo que ela está estressada, aí eu não ligo muito (Menina } 13,13 \text { anos, vítima). } \\
\text { Eu tenho síndrome do pânico, então eu fico muito nervosa em lugar público, cheio, e principalmente quando tem } \\
\text { adolescente (Menina } 45,18 \text { anos, vítima). } \\
\text { As pessoas pegavam justo no meu ponto fraco e eu sentia vontade de gritar, eu sentia vontade de pular a janela e me } \\
\text { suicidar (Menina } 13,13 \text { anos, vítima). }\end{array}$ \\
\hline $\begin{array}{l}\text { O poder das } \\
\text { interações } \\
\text { familiares } \\
\text { positivas }\end{array}$ & $\begin{array}{l}\text { Minha intimidade com meu pai é melhor que com qualquer pessoa. Desde pequeno, tudo que acontecia eu falava para } \\
\text { ele (Menino 9, } 17 \text { anos, agressor). } \\
\text { Meus avós me dão muito respeito, me ensinam muita coisa. Sempre me ajudaram, também, no dia a dia. E tudo que eu } \\
\text { faço, eu falo para eles, e eles tentam me ajudar, me dar dicas (Menina } 45,19 \text { anos, vítima). } \\
\text { Eu e minha mãe conversamos. Eu conto tudo para ela. Ela me dá bastante carinho, também dá bronca quando precisa } \\
\text { (Menino 3, } 13 \text { anos, agressor). } \\
\text { Os momentos com a minha família são importantes. As conversas, até os momentos difíceis não poderiam faltar } \\
\text { (Menino 42, } 16 \text { anos, vítima). } \\
\text { Meus pais não brigam. Nunca brigaram (Menina 13,13 anos, vítima). }\end{array}$ \\
\hline $\begin{array}{l}\text { Possibilidades de } \\
\text { enfrentamento }\end{array}$ & $\begin{array}{l}\text { Contei para o meu pai. Ele me ajudou (Menina } 21,12 \text { anos, vítima). } \\
\text { A gente foi embora, daí no outro dia eles continuaram me ameaçando, ameaçando e eu fui lá na secretaria e falei } \\
\text { (Menino 35, } 13 \text { anos, vítima). } \\
\text { Eu contei para a minha avó e uma vez para a minha mãe. Elas foram na escola reclamar (Menino 33, } 11 \text { anos, vítima). } \\
\text { Uma vez minha mãe até veio aqui na escola, mas não adiantou. Ela falou com os meninos. Ela falou com o [nome de } \\
\text { colega], que estudava aqui. Ela conversou com ele e ele parou. Depois ele saiu da escola e os outros meninos continuaram } \\
\text { (Menina 6, } 13 \text { anos, vítima). } \\
\text { Nesse dia eu fingi que estava passando mal e então eu fui para casa porque não aguentei (Menina 13, } 13 \text { anos, vítima). }\end{array}$ \\
\hline
\end{tabular}

Fonte: Entrevistas semiestruturadas

\section{Categoria temática 4: o poder das interações familiares positivas}

Em geral, o envolvimento familiar dos estudantes entrevistados era positivo, com relatos de manifestação verbal e física de carinho, oportunidades de diálogo e sensibilidade dos pais ou responsáveis para apoiar e reconhecer os problemas dos filhos. Da mesma forma que a boa relação entre as figuras parentais, incluindo a manifestação de afeto, diálogo e respeito, foram observadas. Sobretudo para os agressores, a comunicação positiva na família foi um item destacado, revelando que esse 
não era um problema para esses estudantes que se referiram à existência de diálogos construtivos com as figuras parentais. No grupo das vítimas, o apego do tipo seguro às figuras materna, principalmente, e paterna foi um elemento que se apresentou como determinante para a boa interação do grupo familiar.

\section{Categoria temática 5: possibilidades de enfrentamento}

Essa categoria se refere a dados obtidos apenas junto às vítimas, diferentemente das outras categorias. Nesse sentido, observa-se que alguns adolescentes pediram ajuda para a família e, em alguns casos, para outros adultos na escola. A estratégia utilizada nesses casos foi contar para essas pessoas as situações de agressão vivenciadas. Pais ou responsáveis foram às escolas e buscaram junto à direção solucionar a questão. Contudo, identificou-se que alguns pais, inadequadamente, foram até as escolas e confrontaram os agressores ou não atribuíram importância ao relato dos filhos. Alguns adolescentes não procuraram ajuda ou adotaram estratégias equivocadas de enfrentamento, como a criação de situações escapistas (fingir adoecimento para sair da escola ou choro, por exemplo). Poucas foram as referências a confronto direto das vítimas com os agressores.

\section{DISCUSSÃO}

Os resultados apresentados são similares e podem ser discutidos com outros estudos que demonstram ser a família uma variável relevante para a compreensão do bullying ${ }^{16,22,23}$. No nível individual, percebe-se que, muitas vezes, o comportamento de bullying é baseado na perseguição de objetivos próprios por parte do agressor, seja quando justifica o bullying como forma de também não se tornar uma vítima ou mesmo para "divertir os colegas e se destacar" ${ }^{24}$. Crenças morais, ideias gerais sobre o funcionamento social ou entendimentos sobre a natureza da justiça são construídos pelas famílias e transmitidos aos filhos ${ }^{15,16}$. Por isso, observaram-se aspectos do desenvolvimento moral internalizados positivos em casos em que existem reflexões morais e éticas, mas em alguns casos os pontos indicados foram negativos.

Ainda nesse tópico, os resultados revelaram comportamentos sociais negativos que foram utilizados para escapar das situações de bullying. Tomados em conjunto, estes resultados são consistentes com a ideia de que o bullying é associado à incompetência socioemocional de crianças e adolescentes ${ }^{9}$. Nesse sentido, a qualidade das interações e as condições socioeconômicas da família produzem resultados no desenvolvimento global das crianças e dos adolescentes, influenciando nas habilidades socioemocionais ${ }^{11,15,16,25}$.

Por outro lado, os fatores do microssistema familiar que parecem influenciar no envolvimento dos estudantes em situações de bullying revelaram que é na dinâmica das relações que residem os maiores problemas. Estudos revelaram que quando o grupo familiar apresenta maiores níveis de conflito, falta de supervisão parental, violência doméstica, pouco diálogo e as relações são mediadas pelo estresse ou violência, os filhos são mais propensos a se envolver em situações de bullying ${ }^{8,10,13}$. Do ponto de vista bioecológico, como foram observadas questões positivas na percepção familiar de vítimas e agressores, hipotetiza-se que a adoção de um comportamento social negativo como o bullying não tem como único e exclusivo preditor as interações entre pais ou responsáveis e filhos (processos proximais). Além disso, famílias com padrões de relacionamento e clima familiar positivo são associadas a menores índices de vitimização ou agressão na escola ${ }^{23,25}$.

No que se refere ao mesossistema, sua interface com o bullying se concentrou nas estratégias adotadas pelos pais ou responsáveis para lidar com a situação de bullying vivenciada pelos adolescentes. Uma perspectiva positiva, reconhecida como essencial não apenas diante de situações-limite como o bullying, pois a interação entre a família e a escola é essencial no processo de desenvolvimento dos estudantes ${ }^{23}$.

No que se refere às horas excessivas de trabalho dos pais, na análise da dimensão do exossistema, a literatura apoia a relação entre essa variável e o envolvimento dos filhos em situações de bullying ${ }^{11}$. Resultados que também estão em consonância com as opiniões bioecológicas sobre a importância do tempo dedicado às relações proximais para o desenvolvimento humano ${ }^{15}$.

Dentro do contexto do bullying neste estudo ainda, valores morais, éticos e culturais compartilhados foram identificados como fatores de nível do macrossistema. A esse respeito, percebeu-se que há uma transmissão na família de entendimentos e ações a respeito de como devem ser os comportamentos e as ações dos filhos. Nesse sentido, a literatura indica que a ocorrência do bullying depende dos valores que são disseminados socialmente, baseados no individualismo ou no coletivismo e absorvidos/reproduzidos pelas famílias (como aqueles relacionados aos estereótipos de masculino/feminino, região de origem, por exemplo ${ }^{26}$.

Por fim, nota-se que as experiências de violência são associadas com problemas de saúde e maior insatisfação com a $\operatorname{vida}^{27,28}$. Nesse sentido, um tema que emergiu consistentemente e foi considerado como fator de proteção a ser explorado por programas de intervenção são as boas interações familiares, mensuradas por vínculos fortalecidos, diálogos e afetos. Para a área da saúde, esse aspecto é relevante, principalmente para a atuação de equipes da Estratégia Saúde da Família, que podem executar ações nos domicílios com o objetivo de auxiliar pais e responsáveis a identificar estudantes vítimas ou agressores, bem como podem estar atentos às relações familiares e às práticas parentais, além de poderem prestar atenção no modo como os adolescentes, em geral, resolvem seus conflitos ou como aprendem na família a resolver problemas. Os resultados desta pesquisa podem ser utilizados em iniciativas de formação dos 
profissionais na área da saúde, que têm a família como matriz de ação na atenção primária.

O ponto forte deste estudo está na observação de que a família pode influenciar nas tendências individuais dos adolescentes que se engajam em situações de bullying. Aspectos das interações familiares (boa comunicação, envolvimento afetivo e apego positivo com as figuras parentais) foram percebidos como fatores de proteção para o bullying. Foram identificadas também experiências familiares que podem se relacionar com o envolvimento dos estudantes no fenômeno como: conflitos intrafamiliares, má comunicação, baixo envolvimento afetivo, excesso de carga horária de trabalho dos pais ou responsáveis. Esses resultados destacam a importância de se incluir as famílias em programas de intervenção antibullying.

Entrementes, existem limitações que merecem ser mencionadas. Em primeiro lugar, dada a natureza qualitativa da pesquisa apresentada, seus resultados devem ser considerados como contextuais e provisórios. Em segundo lugar, reconhece-se que os dois constructos de interesse (interações familiares e bullying), bem como a associação entre eles, possuem múltiplas facetas que devem ser abordadas em outros estudos. Recomenda-se, dessa forma, o exame da relação entre as variáveis investigadas em estudos de medida quantitativa ou longitudinal capazes de envolver maiores e diversas amostras para testar hipóteses a partir do modelo bioecológico.

\section{REFERÊNCIAS}

1. Breivik K, Olweus D. An item response theory analysis of the Olweus Bullying Scale. Aggress Behav. 2015;41(1):1-13. http://dx.doi.org/10.1002/ ab.21571. PMid:27539870.

2. Silva JL, Oliveira WA, Silva MAI, Pereira B, Cecilio S. Estudo exploratório sobre as concepções e estratégias de intervenções de professores em face do bullying escolar. Psicol Teor Prat. 2015;17(3):189-99. http://dx.doi. org/10.15348/1980-6906/psicologia.v17n3p189-199.

3. Modecki KL, Minchin J, Harbaugh AG, Guerra NG, Runions KC. Bullying prevalence across contexts: a meta-analysis measuring cyber and traditional bullying. J Adolesc Health. 2014;55(5):602-11. http://dx.doi.org/10.1016/j. jadohealth.2014.06.007. PMid:25168105.

4. Chester KL, Callaghan M, Cosma A, Donnelly P, Craig W, Walsh S, et al. Cross-national time trends in bullying victimization in 33 countries among children aged 11, 13 and 15 from 2002 to 2010. Eur J Public Health. 2015;25(2 Suppl 2):61-4. http://dx.doi.org/10.1093/eurpub/ckv029. PMid:25805790.

5. Oliveira WA, Silva MAI, Mello FCM, Porto DL, Yoshinaga ACM, Malta DC. The causes of bullying: results from the National Survey of School Health (PeNSE). Rev Lat Am Enfermagem. 2015;23(2):275-82. http:// dx.doi.org/10.1590/0104-1169.0022.2552. PMid:26039298.

6. Oliveira WA, Silva JL, Querino RA, Silva MAI. Experiences and perceptions of discrimination related to bullying among Brazilian students. Maltrattamento e Abuso all'Infanzia. 2016;18(1):29-57.

7. Andrade SSCA, Yokota RTC, Sá NNB, Silva MMA, Araújo WN, Mascarenhas MDM, et al. Relação entre violência física, consumo de álcool e outras drogas e bullying entre adolescentes escolares brasileiros. Cad Saude Publica. 2012;28(9):1725-36. http://dx.doi.org/10.1590/S0102-311X2012000900011. PMid:23033187.

8. Oliveira WA, Silva JL, Sampaio JMC, Silva MAI. Students' health: an integrative review on family and bullying. Cien Saude Colet. 2017;22(5):1553-64 http://dx.doi.org/10.1590/1413-81232017225.09802015. PMid:28538926.

9. Higuita-Gutierrez LF, Cardona-Arias JA. Variables of the family, school, and social environment context that determine bullying in adolescents in Medellin, Colombia, 2014. J Sch Violence. 2017;16(1):68-85. http://dx.doi. org/10.1080/15388220.2015.1112807.

10. Santoyo CV, Mendoza BG. Behavioral patterns of children involved in bullying episodes. Front Psychol. 2018;9:456. http://dx.doi.org/10.3389/ fpsyg.2018.00456. PMid:29755379.
11. Espelage DL, Van Ryzin MJ, Holt MK. Trajectories of bully perpetration across early adolescence: static risk factors, dynamic covariates, and longitudinal outcomes. Psychol Violence. 2017;8(2):141-50. http://dx.doi. org/10.1037/vio0000095.

12. Minayo MCS. Violência e educação: impactos e tendências. Revista Pedagógica. 2013;15(31):249-64. http://dx.doi.org/10.22196/rp.v15i31.2338.

13. Oliveira WA, Silva JL, Yoshinaga ACM, Silva MAI. Interfaces entre família e bullying escolar: uma revisão sistemática. Psico-USF. 2015;20(1):121-32. http://dx.doi.org/10.1590/1413-82712015200111.

14. Silva MAI. Bullying among peers at school: a challenge for primary healthcare nurses. Rev Eletr Enf. 2013;15(3):605-6.

15. Bronfenbrenner U. A ecologia do desenvolvimento humano: tornando os seres humanos mais humanos. Porto Alegre: ArtMed; 2011.

16. Patton DU, Hong JS, Williams AB, Allen-Meares P. A review of research on school bullying among African American youth: an ecological systems analysis. Educ Psychol Rev. 2013;25(2):245-60. http://dx.doi.org/10.1007/ s10648-013-9221-7.

17. Wuest J. Grounded theory: the method. In: Munhall PL, editor. Nursing research: a qualitative perspective. Sudbury: Jones \& Bartlett Learning; 2010

18. Thornberg R. 'She's weird!': the social construction of bullying in school: a review of qualitative research. Child Soc. 2011;25(4):258-67. http://dx.doi. org/10.1111/j.1099-0860.2011.00374.x.

19. Minayo MCS. Análise qualitativa: teoria, passos e fidedignidade. Cien Saude Colet. 2012;17(3):621-6. http://dx.doi.org/10.1590/S1413-81232012000300007. PMid:22450402.

20. Bardin L. Análise de conteúdo. São Paulo: Edições 70; 2011.

21. Chávez BL, Yamamoto JM. Content analysis and computational linguistics: its quickness, reliability and perspectives. An Psicol. 2014;30(3):1146-50. http://dx.doi.org/10.6018/analesps.30.3.154931.

22. Lee CH, Song J. Functions of parental involvement and effects of school climate on bullying behaviors among South Korean Middle School students. J Interpers Violence. 2012;27(12):2437-64. http://dx.doi. org/10.1177/0886260511433508. PMid:22328649. 
23. Bibou-Nakou I, Tsiantis J, Assimopoulos H, Chatzilambou P. Bullying/ victimization from a family perspective: a qualitative study of secondary school students' views. Eur J Psychol Educ. 2013;28(1):53-71. http://dx.doi. org/10.1007/s10212-011-0101-6.

24. Thornberg R, Thornberg UB, Alamaa R, Daud N. Children's conceptions of bullying and repeated conventional transgressions: moral, conventional, structuring and personal-choice reasoning. Educ Psychol. 2016;36(1):1-17. http://dx.doi.org/10.1080/01443410.2014.915929.

25. Shetgiri R, Lin H, Avila RM, Flores G. Parental characteristics associated with bullying perpetration in US Children aged 10 to 17 years. Am J Public Health. 2012;102(12):2280-6. http://dx.doi.org/10.2105/AJPH.2012.300725. PMid:23078471.
26. Lee $\mathrm{CH}$. An ecological systems approach to bullying behaviors among middle school students in the United States. J Interpers Violence. 2011;26(8):166493. http://dx.doi.org/10.1177/0886260510370591. PMid:20522882.

27. Oliveira WA, Silva JL, Santos MA, Hayashida M, Caravita SCS, Silva MAI. Interações familiares de estudantes em situações de bullying. J Bras Psiquiatr. 2018;67(3):151-8. http://dx.doi.org/10.1590/0047-2085000000204.

28. Losel F, Bender D. Aggressive, delinquent, and violent outcomes of school bullying: do family and individual factors have a protective function? J Sch Violence. 2014;13(1):59-79. http://dx.doi.org/10.1080/15388220.2013.840644.

Recebido em: Dez. 29, 2017 Aprovado em: Dez. 13, 2018 